DOI: http://dx.doi.org/10.11606/issn.1984-4867.v27i2p274-298

\title{
A Intersecção entre Peregrino e Turista Religioso: os diferentes caminhos ao sagrado
}

The Intersection between Pilgrims and Religious Tourist: the different paths to the sacred

La Intersección entre Peregrinos y Turistas Religiosos: los diferentes caminos al sagrado

Thiago Vinicius Cipriano Rocha ${ }^{1}$

Maria Helena Cavalcanti da Silva Belchior ${ }^{2}$

\section{Resumo}

Dado que o turismo religioso apresenta-se atualmente como um dos segmentos da atividade turística com maior crescimento e desenvolvimento, bem como a exígua produção acadêmica que trata sobre este tema, atrelado a ambiguidades e imprecisões epistemológicas quanto ao uso de categorias temáticas ligadas ao turismo religioso, surge este trabalho com o objetivo de descobrir qual a diferença entre o peregrino e o turista religioso. Buscou-se através do levantamento da origem e desenvolvimento histórico da peregrinação e do turismo religioso, identificar características pertinentes ao peregrino e ao turista religioso, com o intuito de produzir a sistematização teórica acerca da diferença entre estes dois atores. Este trabalho resulta na proposição de um modelo teórico de análise, contendo a sistematização teórica da relação existente entre peregrino e turista religioso, baseado na pesquisa e análise de trabalhos oriundos do campo de estudo do Turismo e de outras áreas afins acerca do turismo religioso. $\mathrm{O}$ presente trabalho comporta uma pesquisa teórica com finalidade aplicada, contendo objetivos de natureza exploratória, utilizando-se da pesquisa bibliográfica e abarcando uma abordagem qualitativa. Concluiu-se que apesar de estarem bastante próximos e apresentarem algumas características semelhantes é possível definir a diferença entre peregrino e turista religioso através da análise mais detalhada das particularidades e atividades desempenhadas por estes dois atores durante os seus deslocamentos. O modelo teórico de análise proposto, mostra-se como uma ferramenta facilitadora na hora de diferenciar o peregrino do turista religioso, auxiliando pesquisadores, leigos e profissionais da área do turismo a melhor definirem estes dois personagens que se cruzam pelos caminhos durante as viagens motivadas pelo sagrado.

Palavras-Chave: Turismo; Turismo Religioso; Peregrinação.

\footnotetext{
${ }^{1}$ Graduação em Turismo pela Universidade Federal de Pernambuco (UFPE). Recife, Pernambuco, Brasil. E-mail: thiago_cipriano_@hotmail.com

2 Mestra em Gestão do Desenvolvimento Local Sustentável pela Universidade de Pernambuco (UPE). Especialização em Administração de Marketing pela Universidade de Pernambuco (UPE) e em Educação a Distância pela Faculdade Integrada de Jacarepaguá (FIJ). Graduação em Turismo pela Universidade Federal de Pernambuco (UFPE). Professora do Departamento de Hotelaria e Turismo da Universidade Federal de Pernambuco (UFPE). Recife, Pernambuco, Brasil. E-mail: maria.hcsilva2@ufpe.br
} 


\begin{abstract}
Knowing that religious tourism is nowadays the segment of the touristic activity with the highest growth and development as well as taking into account that there is very little academic production on the subject, which is full of ambiguity and epistemological inaccuracies regarding the use of theme categories, this work was elaborated with the purpose of discovering the difference between pilgrim and religious tourist. It was tried to identify pilgrim's and religious tourist's relevant characteristics by rising its sources and historic development aiming to produce a theoretical systematization about the difference between this two actors. That was accomplished by a proposition of a summary table as a result of this work, which is based on the research and the analysis of studies in the tourism field and other related areas. This work comprises a theoretical research, with applied and exploratory goals, and uses bibliographic research and qualitative approach. It was concluded that, despite being very similar, it is possible to identify differences between pilgrim and religious tourist with a more detailed analysis of the particularities and activities played by these two actors during displacement. The summary table proposed is a facilitating tool that helps researches, laymen and professionals of the field when defining pilgrim and religious tourist, two players that meet each other on their journeys motivated by the holy.
\end{abstract}

Keywords: Tourism; Religious Tourism; Peregrination.

\title{
Resumen
}

Dado que el turismo religioso se presenta hoy como uno de los segmentos de la industria del turismo de mayor crecimiento y desarrollo, así como la literatura académica magro que se ocupa de este problema, vinculado a ambigüedades e incertidumbres epistemológicas respecto al uso de temas relacionados con el turismo religioso surge este trabajo con el fin de averiguar la diferencia entre los peregrinos y turistas religiosos. Él buscó a través de una encuesta sobre el origen y la historia de la peregrinación y el desarrollo del turismo religioso, la identificación de las características relevantes a peregrinos y turistas religiosos, con el fin de producir la sistematización teórica sobre la diferencia entre estos dos actores. Se traducen en proponer un análisis de modelo teórico, que contiene la sistematización teórica de la relación entre los peregrinos y turistas religiosos, basado en la investigación y el análisis de los proyectos derivados en el campo del turismo de estudio y otras áreas relacionadas sobre el turismo religioso. Este trabajo consiste en una investigación teórica con fines aplicados, que contiene objetivos de exploración, utilizando la literatura y que abarca un enfoque cualitativo. Se concluyó que a pesar de que están muy cerca y presentes algunas características similares pueden definir la diferencia entre peregrinos y turistas religiosos a través de un análisis más detallado de las características y las actividades realizadas por estos dos actores durante sus turnos. El análisis teórico modelo propuesto, se muestra como una herramienta facilitadora con el fin de diferenciar el turismo religioso peregrino, ayudar a los investigadores, los no expertos y las mejores definiciones de área del turismo de estos dos personajes que se cruzan los caminos para los viajes motivados por sagrado.

Palabras Clave: Turismo; Turismo Religioso; Peregrinación. 


\section{Introdução}

O turismo religioso mostra-se como um segmento bastante significativo e crescente dentro da atividade turística atualmente. Comparando-se os 8,1 milhões de viagens domésticas no Brasil movidas pela fé em 2010 (G1, 2010), em relação aos 17,7 milhões que constam nos dados recentes do Ministério do Turismo (2015), comprova-se o aumento significativo que os deslocamentos por motivos religiosos sofreram nos últimos anos.

No Brasil, muitos destinos turísticos se desenvolveram e se baseiam exclusivamente na exploração do turismo religioso, fazendo desta atividade seu principal produto. Segundo o Ministério do Turismo (2013), o Brasil possui 344 cidades que podem atender ao desejo do viajante que está em busca da prática religiosa. Deste número, 117 destinos possuem calendário fixo de eventos relacionados à fé, a maior parte deles católicos (MTur, 2013). São exemplos: Juazeiro do Norte no Ceará, São Severino dos Ramos em Pernambuco, Basílica do Santuário de Nossa Senhora Conceição Aparecida em São Paulo, Bom Jesus da Lapa na Bahia, Nova Tentro em Santa Catarina, entre outros. Segundo Costa et al. (2014, p. 5):

"[...] pelo Brasil ser um país onde a fé católica predomina, abrangendo 64,6\% de todo o contingente populacional brasileiro, segundo o Censo Demográfico realizado pelo Instituto Brasileiro de Geografia e Estatística (IBGE), em 2010, os espaços turísticos religiosos encontrados no Brasil são na sua maioria católicos" (COSTA, 2014, p. 5).

Como um segmento, o turismo religioso ainda não é muito pesquisado e documentado. São poucos os estudos estatísticos confiáveis sobre a sua dimensão e valor dentro da atividade turística como um todo, principalmente porque são poucos os destinos que medem de forma eficaz o número de chegadas de visitantes usando uma classificação que se refere à "religião", "peregrinação" ou "romaria". Outro problema comum com a medição do turismo religioso diz respeito à definição inconsistente do segmento e dos conceitos nele envolvidos.

Após pesquisa bibliográfica, observou-se que nesta mesma direção a produção acadêmica sobre o turismo religioso despertou o interesse de pesquisadores e estudiosos, a partir dos últimos 15 anos. Outro ponto observado é o fato de que muitas produções são advindas de outros campos de estudo como, por exemplo, antropologia, sociologia, geografia e teologia, o que não representa um problema, mas pelo contrário, uma necessidade natural do turismo, por se tratar de uma atividade multidisciplinar, e que deve valer-se de estudos de outras áreas. O que falta são trabalhos no campo do turismo que sistematizem esta produção dispersa e leve em consideração os diferentes atores, conceitos, conflitos e intersecções presentes dentro do turismo religioso. 
A falta de conhecimento, preconceitos e desentendimentos sobre o assunto ainda existem e dificultam o pleno desenvolvimento e planejamento do turismo religioso e o acordo entre as partes que atuam neste segmento. A atualidade do tema em voga abre uma nova porta para o diálogo entre a atividade do turismo, a Igreja Católica, a comunidade e os visitantes de espaços sagrados, em vista de desenvolver o turismo religioso de maneira sustentável e benéfica para todos os envolvidos.

Gradativamente a indústria turística tem investido e participado de ações cada vez mais diretas nos centros de visitação religiosa, visando estimular o aumento do número de visitantes e consequentemente o lucro. A Igreja Católica, em contrapartida, vem tentando acompanhar o crescimento do turismo religioso de maneira a orientar esta atividade de forma alinhada aos princípios e preceitos desta religião. O catolicismo abre-se para o turismo religioso como uma maneira contemporânea de religiosidade e uma oportunidade única de evangelização (VILAS BOAS, 2012).

A pergunta que deu origem ao problema no qual este trabalho está baseado foi: Qual a diferença entre peregrino e turista religioso? Este questionamento surgiu a partir da constatação da exígua produção acadêmica no campo do turismo referente ao turismo religioso, mas precisamente quanto à disparidade entre o turista religioso e o peregrino. Observa-se que nos locais sagrados de visitação é possível encontrar peregrinos, romeiros e turistas religiosos, cada um com uma motivação pessoal, desempenhando atividades divergentes ou convergentes, mas que em diversos momentos estes atores se cruzam e se relacionam de diferentes maneiras.

Este trabalho objetiva, no primeiro momento, relatar a origem e desenvolvimento histórico da peregrinação e do turismo religioso. Em seguida, busca-se identificar, com base na produção acadêmica sobre o turismo religioso, características pertinentes ao peregrino e ao turista religioso. Procura-se confrontar as diferentes definições para estes conceitos de acordo com a visão de diversos autores da área do turismo e de outros campos de estudo. E por fím, será realizada a sistematização teórica sobre os conceitos de peregrino e turista religioso.

\section{Metodologia}

Este trabalho apresenta uma pesquisa com finalidade aplicada. Para Silva e Menezes (2005, p. 20) este tipo de pesquisa "objetiva gerar conhecimentos para aplicação prática e dirigidos à solução de problemas específicos". 
Quanto à área de atuação da ciência, configura-se como uma pesquisa teórica. Segundo Demo (2000, p.20), esta trata-se da pesquisa que é "dedicada a reconstruir teoria, conceitos, ideias, ideologias, polêmicas, tendo em vista, em termos imediatos, aprimorar fundamentos teóricos". A pesquisa teórica tem como objetivos definir leis, estruturar sistemas e modelos teóricos, relacionar e aproximar hipóteses, apresentando um papel importante na criação de condições para a intervenção na realidade.

O trabalho tem objetivos com natureza exploratória. Segundo Gil (2008) este tipo de pesquisa busca proporcionar maior familiaridade com o problema. Geralmente, assume a forma de pesquisa bibliográfica e estudo de caso. Como pode ser observado, é possível dizer que a pesquisa exploratória é utilizada principalmente para os problemas pouco explorados, buscando uma visão panorâmica e a aproximação do problema ao pesquisador.

O procedimento técnico utilizado para a realização deste trabalho foi a pesquisa bibliográfica. Que segundo Gil (2008, p. 23), têm-se esse tipo de pesquisa quando ela é "elaborada a partir de material já publicado, constituído principalmente de livros, artigos de periódico e atualmente com material disponibilizado na internet". Este tipo de pesquisa objetiva recuperar o conhecimento científico acumulado sobre determinado problema.

Por fim, o presente trabalho apresenta uma pesquisa com abordagem qualitativa, onde as informações obtidas não podem ser quantificáveis, os dados alcançados são de natureza descritiva e são analisados indutivamente.

\section{Antecedentes Históricos dos Deslocamentos por Motivos Religiosos}

Abordar os deslocamentos religiosos é tratar da própria história da humanidade, pois, sabe-se que desde que o homem passou a se reconhecer em sociedade ele criou mecanismos e simbolismos para manifestar a sua fé e sua crença, e os deslocamentos estiveram intrínsecos a este processo. Com o passar dos anos, os deslocamentos trouxeram certo desenvolvimento e estruturação, turística ou não, para as sociedades.

Em um ponto de vista histórico, Seccal (2009, apud NADAIS, 2010, p. 10) explica que o turismo religioso originou-se a partir dos deslocamentos para celebrar episódios litúrgicos ligados aos ciclos agrícolas, e ressalta que este não pode ser igualado a qualquer outra atividade turística, em vista do seu caráter espiritual. Oliveira (2004, p. 15) completa dizendo que "o ato de peregrinar tende a ser, antes de tudo, um ritual das origens nômades dos grupos humanos. 
Peregrina-se em busca de algo mais significativo; em busca da vida que supera a simples sobrevivência". A história aponta que o ser humano, continuamente, procura sentido e significado no seu cotidiano e, por isso, é impelido a deslocar-se por um combinado de motivações: religião, prazer, educação, saúde, trabalho, tempo livre, etc.

As peregrinações cristãs tradicionais e primitivas, junto com suas motivações espirituais, originalmente não dependiam de condições técnicas, ambientais ou de infraestrutura ligadas aos serviços turísticos. Com o passar do tempo é possível observar a mudança dessa realidade quando os deslocamentos religiosos começam a modificar a paisagem com o surgimento dos primeiros estabelecimentos ligados ao turismo nas regiões receptoras de peregrinos. Em outras palavras, Ribeiro (2003, p. 2) afirma que a “[...] institucionalização do turismo está intimamente ligada às peregrinações [...]", as quais, no decurso do tempo, foram acompanhadas pelo surgimento de pousadas, hospedarias na beira de caminhos, povoados, portos e cidades. Nesses locais, os peregrinos pernoitavam, descansavam, alimentavam-se e encontravam mantimentos para prosseguir viagem. Guerra (1989, p. 13) afirma que "o turismo religioso é o parente mais nobre, mais antigo e mais consistente de toda a família turística". Nesse mesmo sentido, Oliveira (2004, p. 13) diz que:

O turismo religioso tem sua origem no exercício contemporâneo da peregrinação. O turista religioso, nesses termos, não deixa de ser um peregrino. Apenas atualiza essa prática adaptando sua viagem - ora parcial, ora plenamente - às características do processo turístico, conforme o contexto socioeconômico do fenômeno religioso em questão. (OLIVEIRA, 2004, p. 13)

Sob esse prisma, ainda de acordo com o autor, a peregrinação, como uma forma de expressão de fé, começou a ser tratada recentemente como turismo religioso, representando uma nova percepção para um fenômeno milenar.

Segundo o pensamento de Carneiro (2004, p. 92):

Em termos analíticos, a peregrinação e o turismo se apresentam como duas estruturas de valores e sentidos distintas. No entanto, no nível empírico, estes campos aparecem sempre imbricados, tornando suas fronteiras bastante fluidas e híbridas, constituindo-se em estruturas de significados que se articulam e se combinam de várias maneiras formando arranjos sempre renovados e em permanente mutação. De acordo com Steil (1999), nesta imbricação podemos ver surgir um novo campo que podemos denominar de turismo religioso. Esta nova área híbrida conjuga elementos ditos "religiosos" com uma estrutura turística de significados e valores em um permanente diálogo, sem que um predomine sobre o outro. (CARNEIRO, 2004, p. 92). 
Com o advento da revolução industrial, do capitalismo, urbanização e as transformações no estilo de vida decorrentes da modernidade e pós-modernidade, é possível observar uma mudança de sentido e significado atribuído aos deslocamentos religiosos. Peregrinação e romaria vão aos poucos assumindo a feição de turismo quando estas práticas, antes rituais sagrados, passam a estar associados aos momentos profanos e de lazer, como festas, arraiais, entre outros eventos.

Ribeiro (2003, p. 2) observa que nas movimentações religiosas no século XIX, já estavam incluídos o lazer e o desfrute do tempo livre, em oposição ao trabalho, como elementos importantes de convivência e sociabilidade entre os romeiros: "compartilhar não apenas a fé como também a intenção de desfrutar momentos de lazer em conjunto, onde era rompido o cotidiano de trabalho". A romaria ganha ares de celebração e festa, na qual "o grupo preparavase não apenas espiritualmente como também para desfrutar de um acontecimento social".

Neste sentido, o turismo religioso surge como uma oportunidade de unir o lazer e a religião, além de renovar ritos e práticas religiosas em uma forma contemporânea. Silveira (2003, p. 39) justifica a inclusão do lazer no turismo religioso ao afirmar que o termo é uma categoria surgida no mundo do mercado/marketing, que foi encapada nos discursos teóricos, inclusive da academia cientifica do turismo.

Segundo o estudo de Vilas Boas (2012, p. 34) "o turismo religioso emergiu na Europa do pósguerra". O autor destaca ainda que este fenômeno foi impulsionado "com o decréscimo da prática religiosa institucional e o aumento da secularização da sociedade e o desenvolvimento das viagens (automóvel e autocarro)" (Idem).

No final do século XX, o turismo religioso ganhou uma maior dimensão. Para Santos (2006, p. 240), o turismo religioso é um fenômeno recente, com poucas décadas de existência onde "não são consideradas as modalidades históricas de peregrinação, quando, as práticas religiosas mais institucionalizadas entram em decadência pela secularização, e, as viagens de automóvel se desenvolvem ocorrendo uma diminuição da peregrinação tradicional". Para a autora o turismo religioso começa então a ser explorado pelas agências de viagem através de visitas a lugares considerados sagrados, nascendo "das mesmas circunstâncias sociais e econômicas que conduziram, em geral, ao turismo de massas" e torna-se, sem dúvida, uma nova forma de prática turística. 
O turismo religioso, assim como o próprio turismo, apresenta-se como um fenômeno múltiplo, de caráter complexo, abrangendo diferentes significados e motivações e podendo ser analisado e compreendido por meio de abordagens diversas. Christotffoli et al. (2012, p. 601) ressaltam que os estudiosos ao analisarem os deslocamentos por motivos religiosos, assim como as pessoas que praticam estes deslocamentos, não podem banalizá-los e colocá-los em um pacote único de produtos e serviços, "antes de tudo, faz-se necessário também conhecer os discursos dos que se deslocam, os nomes que estas pessoas dão as suas experiências e o que elas consideram como fundamental para a experiência que irão vivenciar".

\section{Raízes da Peregrinação}

Peregrinar significa estar a caminho. Ao falar de peregrinação associa-se imediatamente a palavra ao ato de caminhar em direção a algo, e o senso comum faz a ligação deste ato com o sagrado. É possível dizer que este fenômeno pode ser encontrado em quase todas as religiões, desde a pré-história até os atuais círculos sociais. No mundo clássico, nas religiões do Oriente, e no mundo muçulmano vê-se florescer as peregrinações.

É possível encontrar nas palavras de Santos (2000, p. 39) o sentido e o significado que a peregrinação assumia para os primeiros povos. $\mathrm{O}$ autor destaca que a história das peregrinações confunde-se com a própria história das crenças e religiões:

Em tempos remotos, era comum a crença em divindades locais, Os seres divinos tinham poderes apenas sobre certas forças ou locais. Sendo assim, os deuses das montanhas não tinham poderes sobre as planícies e vice-versa. Quando uma pessoa pertencente a uma tribo das montanhas encontrava-se longe de seu local de origem e necessitava de ajuda divina, esta peregrinava de volta às montanhas para pedir a seu Deus. Foi assim que, a partir das crenças dos homens primitivos, originaram-se as peregrinações. (SANTOS, 2000, p. 39).

Vilas Boas (2012, p. 26) afirma que o 'sentir' religioso impulsionou o fenômeno dos deslocamentos "desde o antigo Egito com as peregrinações às cidades de Busiris, Tebas, Luxor e Abidos em honra ao deus Osíris, passando pelos Hititas e Houritas que tinham um grande número de deuses, pelos Hebreus que vinham a Jerusalém participar na Páscoa”. Os Hebreus tinham ainda três festas em que ocorriam peregrinações: a festa do pão ázimo (Mazzoth); a festa do Pentecostes (Shabuath) e a festa das tendas ou festa de Javé (Sukkoth).

A lista de povos que possuíam a peregrinação como ato sagrado é ainda encorpada por Santos (2000, p. 39): 
Os egípcios peregrinavam ao Oráculo de Amon, em Tebas; os gregos ao Oráculo de Apollo, em Delfos; ao Templo de Ártemis (uma das sete maravilhas do mundo antigo), em Éfeso; ao templo de Palias Atena, em Atenas; ou ao Templo de Zeus, em Olímpia; os astecas à Quetzalcôatl; os incas à cidade de Cuzco e ao lago Titicaca. (SANTOS, 2000, p. 39).

No mundo grego é possível identificar deslocamentos por motivos religiosos por volta de 2500 anos A.C. onde grande aglomeração de pessoas se reunia nos jogos olímpicos, eventos organizados em homenagem ao Deus Zeus, conforme afirma Colli (2004, p. 6). Segundo Mazón (2001, apud DIAS; SILVEIRA, 2003, p. 19) nesse período “já ocorriam manifestações do que podemos denominar de turismo religioso, com peregrinações de todo o mundo helênico para regiões como Delfos".

Trazendo as peregrinações para o universo do Cristianismo, observa-se que entre os séculos I e IV existem escassas menções relacionadas às peregrinações cristãs, devido não só a "tentativa do cristianismo de se distanciar das práticas judaicas de peregrinação [...] mas também graças às desumanas perseguições que os cristãos sofreram" neste período, fatores ressaltados por Vilas Boas (2012, p. 27).

Em 313 o imperador romano Constantino reconhece legalmente o Cristianismo, a partir daí, o ambiente torna-se favorável para o desenvolvimento das peregrinações cristãs, principalmente a Roma e Jerusalém. Já na Idade Média, “assistimos ao apogeu das peregrinações, devido à diversidade e ao grande número de relíquias associadas a Cristo e a Maria, à disseminação do culto dos santos, de festas e romarias para visitar os seus templos e sepulcros" (VILAS BOAS, 2012, p. 27-28).

Nesse período, cabe pontuar a intersecção entre turismo e peregrinação. Muitos estudiosos defendem que a partir desse momento ocorre a institucionalização do turismo, estando este intimamente ligado ao desenvolvimento das peregrinações "que ao longo do tempo deram origem ao aparecimento das pousadas, hospedarias na beira dos caminhos, povoados, portos e cidades", como afirma Ribeiro (2003, p. 2). Observa-se então que a ideia de turismo surgiu como uma necessidade de prover e sistematizar alimentação, abrigo, e proteção para aqueles que viajavam pelas estradas europeias, cominando no aparecimento de estabelecimentos que no futuro iriam se chamar pousadas, hospedarias e restaurantes.

No período do Renascimento, devido à crescente urbanização e ao surgimento de novos pensamentos filosóficos (como por exemplo, o humanismo e o liberalismo), o poder do cristianismo foi diminuído e consequentemente o fluxo de peregrinações. Somando-se a isso, 
Ribeiro (2003, p. 2) informa que "nos séculos XVI e XVII, vários santuários começaram a distinguir-se em locais afastados das cidades, em meio à natureza inóspita”, o que representa um movimento contrário ao desenvolvimento das cidades e uma atribuição de significados místicos a elementos como grutas, montanhas, rios, etc. Vilas Boas (2012, p. 28) referência ainda uma segunda causa para o arrefecimento das peregrinações, "a descoberta do Novo Mundo, de novos lugares e culturas que eram vistas como campo de evangelização e oportunidade para obtenção de riqueza e exploração".

Durante a Idade Moderna, "os novos compromissos do trabalho faziam escassear o tempo disponível para cumprir as longas rotas da fé. As manifestações de devoção tornavam-se cada vez mais estáticas e restritas a determinados locais, previamente delimitados”, é o que pontua Ribeiro (2003, p. 2). A autora afirma ainda que aqueles que participavam de peregrinações procuravam trazer "uma relíquia ou lembrança, que pudesse ser compartilhado com os que não foram" (Ibidem). Estes objetos acabavam se tornando uma forma de vinculo e confraternização entre os peregrinos e os demais, além de deixar viva a ideia do ritual.

Com o advento da Idade Contemporânea, englobando o estilo de vida agitado, devido ao espaço ocupado pelo trabalho e compromissos, as implicações da revolução industrial e do capitalismo, ocorre à diminuição do tempo que as pessoas dedicavam à religião, às devoções e às questões do sagrado. Depois de um período de baixo fluxo de peregrinações, a partir do século XIX ocorre um reflorescimento desta atividade com novos sentidos, Vilas Boas (2012, p. 29) afirma que "assiste-se a um renascer religioso, com a reconstituição de imensas ordens religiosas que impulsionaram novamente as peregrinações".

Nos tempos atuais, observa-se que as peregrinações continuam sendo uma instituição com forte poder de concentração e conexão humana "pois se constituem em oportunidade de afirmar a vitalidade e a unidade de um grupo, e, assim, são vividas, simultaneamente, como cerimônia religiosa e como lazer" (RIBEIRO, 2003, p. 2).

\section{Turismo Religioso e Peregrinação: faces e interfaces}

A concepção do termo 'turismo religioso' abarca certa complexidade. Por se tratar de um conceito formado por duas instituições, o turismo e a religião, que apresentam valores e limitações encerrados em si mesmo, mas que juntos dão lugar a uma nova realidade que comportam características dos dois elementos. 
A cartilha "Turismo Cultural: Orientações Básicas" criada pelo Ministério do Turismo (MTur) em 2008 ressalta que os deslocamentos motivados por interesses religiosos, místicos, esotéricos, cívicos e étnicos são entendidos por esta entidade como recortes no âmbito do Turismo Cultural "e podem constituir outros segmentos para fins específicos: Turismo Cívico, Turismo Religioso, Turismo Místico e Esotérico e Turismo Étnico” (MTUR, 2008, p. 18).

Ainda segundo o texto presente na cartilha "o Turismo Religioso configura-se pelas atividades turísticas decorrentes da busca espiritual e da prática religiosa em espaços e eventos relacionados às religiões institucionalizadas". Entende-se por religiões institucionalizadas aquelas que apresentam doutrina, hierarquia, estruturas, rituais, sendo o grupo que engloba aquelas de origem oriental, afro-brasileiras, espíritas, protestantes e católicas (MTUR, 2008, p. 18).

É possível observar o viés de religiosidade popular que deu origem aos deslocamentos religiosos e, consequentemente, ao turismo nas palavras de Oliveira (2004, p. 52) quando o autor afirma que "o turismo religioso não é de religiosos, nem de religião. É um turismo motivado pela religiosidade, pela cultura religiosa. Portanto, onde quer que essa cultura se manifeste [...] poderá existir um turismo religioso (com ou sem profissionalismo)". Na síntese que se forma a partir do turismo religioso, elementos como a cultura popular, a urbana e a religiosa “juntam-se, tornando-se um amálgama, um híbrido” (SILVEIRA, 2007, p. 36).

Vilas Boas (2012, p. 36) diz que a correta definição de turismo religioso trata-se de um exercício de aproximação. Para o autor, este segmento do turismo diz respeito a um fazer turístico capaz de manifestar algum sentido de religiosidade, e "é exatamente na religiosidade - no ato popular de professar o sistema de crenças chamado de religião - que o turismo religioso pode ser comparado às peregrinações e romarias aos lugares sagrados, em momentos também sagrados".

Na definição oficial utilizada como base tanto pela Igreja Católica quanto por acadêmicos, criada durante a Conferência Mundial de Roma, realizada no ano de 1960, têm-se o seguinte argumento:

O turismo religioso é compreendido como uma organização que movimenta inúmeros peregrinos em viagens pelos mistérios da fé ou da devoção a algum santo. A sua prática efetiva realiza-se de diversas maneiras: as peregrinações aos locais sagrados, as festas religiosas que são celebradas periodicamente, os espetáculos e as representações teatrais de cunho religioso, e os congressos, encontros e seminários, ligados à evangelização. (RIBEIRO, 2003, p. 3).

Para Steil (1998, p. 4), o significado é bem preciso: "pode-se falar em turismo religioso quando o sagrado migra como estrutura de percepção para o cotidiano, para as atividades festivas, para o consumo, para o lazer". Assim, os turistas passam a participar de eventos não apenas 
vinculando-os à tradição cristã, mas relacionando-os a uma experiência inusitada, espiritual e consumista ao mesmo tempo.

Andrade (2000, p. 77) define o turismo religioso como "o conjunto de atividades, com utilização parcial ou total de equipamentos, e a realização de visitas a receptivos que expressam sentimentos místicos ou suscitam a fé, a esperança e a caridade aos crentes ou pessoas vinculadas a religiões". Ribeiro (2010, p. 8) apresenta uma definição claramente baseada no conceito do MTur, dizendo que "turismo religioso é aquele empreendido por pessoas que se deslocam por motivações religiosas ou para participação em eventos de caráter religioso. Compreendem romarias, peregrinações e visitação a espaços, festas, espetáculos e atividades religiosas".

Oliveira (2004, p. 19) afirma que relacionar o turismo religioso como sendo peregrinação para uma celebração cristã é também lembrar que o "termo religião (de re-ligare ou re-eligiare) é latino, medieval e originário da Igreja Católica Romana”. Portanto, não se refere ao turismo de todas as religiões - de forma tão universal - nem ao turismo dos praticantes/sacerdotes do catolicismo - de maneira tão restritiva. Trata-se segundo o autor, do turismo feito pelo peregrino contemporâneo, mais ou menos influenciado pela cultura cristã ocidental, no contexto de uma sociedade periférica denominada Brasil.

Para o conceito de peregrino é possível encontrar no dicionário Michaelis (2008, p. 658) a seguinte definição: Pe.re.gri.no (lat peregrinu) adj+sm 1 Que ou quem sai ou anda em peregrinação; romeiro. 2 Estrangeiro, estranho. Observa-se que quanto a sua etimologia, a palavra peregrinar deriva do latim, partindo da junção da preposição per (através ou por) e do substantivo ager (campo, território, região ou país), que segundo o entendimento de Vilas Boas (2012, p. 24) "significa aquele que viaja ao, para o estrangeiro, que vem do estrangeiro, que viaja pelos campos, que viaja para longe, ir em romaria (peregrinar pelos lugares santos)".

Ainda segundo Vilas Boas (Idem.), o termo pelegrinus foi utilizado até o século XI pelo mundo romano com um sentido profano, significando aqueles que eram estrangeiros e não tinham "direito a cidade" (cidadania). No período medieval, época das cruzadas e das grandes catedrais, o termo sofreu uma ressignificação e passou a designar o cristão que caminha à procura do sagrado.

O senso comum normalmente entende que a peregrinação é uma jornada empreendida por motivações devocionais a um dado espaço reconhecido como sendo sagrado pelo indivíduo. As finalidades desses deslocamentos podem ser variadas: pagar promessa, render graças, fazer penitências, etc. 
Carneiro (2004, p. 77) afirma que no livro mais citado sobre o Caminho de Santiago, encontrase a seguinte definição de peregrinação: "Do ponto de vista geral, histórico-religioso, não é outra coisa que a viagem, empreendida individual ou coletivamente, para visitar um lugar santo, onde se manifesta de um modo particular a presença de um poder sobrenatural" (Vázquez de Parga, Lacarra e Uria Riu, 1948).

De acordo com Dias, (2003, p. 22) a palavra peregrino tem sido mais associada à experiência individual vivida pelo que faz a jornada. Para este, o deslocamento ao santuário ocorre devido a sua espiritualidade, seja para cumprir votos feitos anteriormente, pagar uma promessa, agradecer uma benção, reconhecer uma graça recebida, participar de uma festa religiosa importante, entre outras questões. "O peregrino (o romeiro) não se sente como um turista e, embora utilize as instalações turísticas, na realidade não apresenta o mesmo comportamento" (DIAS, Idem).

Em verdade, observa-se que muitos autores ligam o conceito de turismo religioso com o de peregrinação, enquanto outros advogam a autonomia do termo para melhor entendimento e melhor desenvolvimento das atividades.

\section{Peregrino versus Turista Religioso}

Analisando os atuais papeis dos peregrinos e dos turistas religioso, observa-se que são produzidos novos modos de vivência religiosa, embutidas num espaço pós-moderno que leva a um entrecruzamento de motivações e disposições seja do turista, seja do peregrino. Como afirma Santos (2006, p. 77) "novos e velhos peregrinos, coexistindo antigas tradições de deslocamento, em resultado de promessas ou objetivo de salvação, com finalidades pós-modernas de fuga ao quotidiano urbano ou de busca radical de novos horizontes de transcendência”.

Em seu estudo sobre a Pastoral do Turismo, Vilas Boas (2012, p. 39) entende que a peregrinação pode ser um dos elementos presentes dentro do turismo religioso ou existir por si só. O autor distingue peregrinação e turismo religioso segundo as motivações destas personagens, entendendo que cada uma delas tem o seu campo de ação, e eles por si só não podem encerrar e delimitar todos os tipos de deslocamentos religiosos. Para o autor:

A peregrinação ordena uma entrega mais empenhada e intensa da pessoa ao sagrado, à transcendência. Ela comporta um conjunto de rituais bem peculiares e bem restritos (promessas, ascese espiritual, votos, penitências, etc.) que reclamam um empenho total do crente, do peregrino. Muito 
dificilmente observamos este rigoroso enlace com o divino nos turistas religiosos. Todavia, o turismo religioso não fica desprovido das atividades religiosas e muito menos de uma certa motivação religiosa. (VILAS BOAS, 2012, p. 39).

Sobre a diferença entre peregrinos e turistas, Beni (2000, p. 422) apresenta a seguinte percepção: "o turista é aquele que se desloca para outros lugares a partir de escolhas e motivações variadas, o peregrino se concentra na motivação religiosa, contudo é um turista potencial". Esta afirmação justifica-se pelo fato de existir a presença do consumo na viagem com fins religiosos, seja com acomodação, alimentação, compra de lembrancinhas e artigos religiosos, etc., que podem ser comuns tanto a turistas quanto peregrinos.

Um primeiro elemento distintivo entre peregrino e turista religioso tem a ver com a posição religiosa que o mesmo assume diante da sua religião. Vilas Boas $(2012$, p. 39) apresenta alguns pontos de ligação e distanciamento entre estes dois universos, sendo o primeiro deles o fato de que "o peregrino apresenta-se como um "crente devoto" de algum lugar sagrado, santo ou invocação. Por sua vez, o turista religioso apresenta-se como "turista crente", isto é, manifestando cortesia e respeito diante da religião". Observa-se que enquanto o peregrino é movido pela procura da satisfação e conforto espiritual, buscando aumentar a sua religiosidade e obtenção de bênçãos, o turista além de participar, descomprometidamente, nas atividades religiosas, acrescenta outras atividades a sua viagem.

No que diz respeito às linguagens que um e outro empregam, vemos nos peregrinos sinais e semblantes que expressam fé e penitência. Segundo Vilas Boas (2012, p. 40) as atitudes de fé do turista religioso/peregrino surgem entrelaçadas com a "contemplação da natureza, da cultura, a deleite pela beleza do local, o enriquecimento do conhecimento e, até mesmo, a oportunidade de repouso". Deste modo, entendemos que para o peregrino o deslocamento é um fim, porque é impelido pelo desejo de se aproximar espiritualmente do sagrado e de se relacionar com ele. Para o turista religioso é um meio, pois ele utiliza a viagem como pretexto para experimentar e interiorizar outras realidades.

Sharpley e Sundaram (2005, apud SERRALLONGA e HAKOBYAN, 2011, p. 69) argumentam que a relação entre o turismo e a religião pode ser conceituada como um processo baseado na intensidade de motivação religiosa. A este respeito os autores fazem referência ao modelo criado por Smith (1992), que representa graficamente dois extremos (ver figura 1): de um lado encontra-se a peregrinação sagrada, uma viagem cujos motivos são a fé, a religião e a realização espiritual; em outro extremo estão os turistas seculares que tentam satisfazer alguma 
necessidade pessoal ou espiritual através do turismo. Entre esses dois extremos, é possível encontrar várias formas de turismo religioso motivados, em maior ou menor grau, por necessidades religiosas ou culturais ou ainda com base na busca pelo aumento de conhecimento.

\begin{tabular}{|c|c|c|c|c|}
\hline Porgatiag & & $\begin{array}{l}\text { Turinto } \\
\text { rasigioso }\end{array}$ & \multicolumn{2}{|r|}{ Turitisno } \\
\hline 愹 & bs & a & $d$ & \\
\hline Bagrado & & 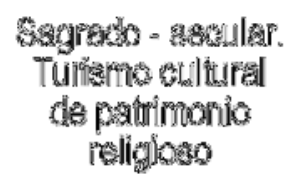 & & Sesular \\
\hline
\end{tabular}

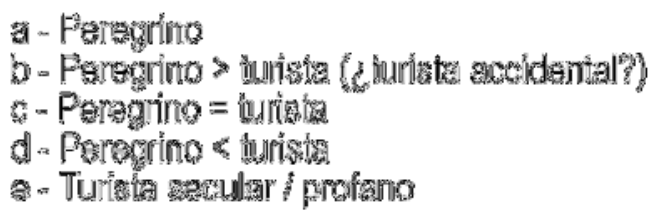

Figura 1: Delimitação entre Peregrino e Turista Religioso

Fonte: Smith (1992, apud SERRALLONGA e HAKOBYAN 2011).

Observa-se que para os autores a motivação é o elemento básico de diferenciação entre os dois fenômenos (turismo e peregrinação).

Sabe-se que as características que norteiam o turismo religioso e aqueles que o praticam se modificam de acordo com o lugar, o contexto social, e a motivação da viagem. O grupo de pessoas inseridos neste segmento do turismo é sempre envolto de discussões e limitações conceituais. Os eventos e espaços sagrados estão revestidos de um caráter "multifuncional, bem como polissêmico dificultando estabelecer fronteira precisas de classificação sobre a demanda deste segmento" (ARAGÃO e MACEDO, 2011, p. 40). Apesar das divergências, alguns autores tratam da intersecção e das características que distinguem o perfil do turista religioso e do peregrino.

Segundo afirmam Abreu e Coriolano (2003, p. 79) “a viagem para o romeiro é a satisfação espiritual da busca do místico, sendo na maioria das vezes um ato de sacrifício. [...] Para o turista, é uma procura de satisfação religiosa mais do que prazer material [...]". Pode-se dizer que o turista religioso combina na sua viagem o prazer com a fé, mas a motivação maior é o prazer de viajar, conhecer coisas e lugares novos, diferente do peregrino.

Além do critério da motivação religiosa, Santos (2006, p. 280) aponta outros "critérios acessórios", como por exemplo, a duração da viagem, que é menor no caso do turista religioso, 
"pois tendencialmente demoram menos tempo no lugar sagrado de destino, enquanto que as peregrinações absorvem mais tempo; o tempo religioso está também influenciado pelo calendário religioso e, por isso, é empreendido de acordo com grandes eventos de natureza religiosa". Ao tratar do critério relacionado ao consumo de bens e serviços, Beni (2000, p. 422) afirma que os "peregrinos assumem um comportamento de consumo turístico, pois utilizam equipamentos e serviços com uma estrutura de gastos semelhante à dos turistas reais”.

Quanto ao critério social dos visitantes, Ribeiro (2003, p. 4) afirma que nas classes sociais mais abastadas, e com maior nível sociocultural, o turismo religioso é realizado com maiores investimentos e maior duração de tempo, estando quase sempre vinculado a outra atividade simultânea. Para a autora:

O conforto e o planejamento são primordiais nesse tipo de peregrinação, uma vez que o peregrino possui recursos financeiros e culturais para estabelecer o roteiro e o gerenciamento do seu tempo. Nesse caso, a penitência adquire outro sentido, podendo ser encarada como uma obrigação do fiel de conhecer e aprofundar a sua fé, através da visita aos locais considerados sagrados. (RIBEIRO, 2003, p. 4).

No entanto, é preciso observar que alguns fiéis ainda consideram que, em se tratando de turismo religioso, as dificuldades fazem parte da experiência. Para Ribeiro (2003, p. 4) essas dificuldades se "apresentam como uma espécie de aventura mística, tendência que pode ser notada em tempos recentes, mais comum entre os jovens e incentivada pelos chamados roteiros alternativos, que resgatam a mística da fé aliada ao contato com a natureza".

Em se tratando do critério do destino final da viagem, o estudo de Serrallonga e Hakobyan (2011, p. 65) afirma que para um peregrino, todo o caminho da peregrinação esta dirigido para o destino final, que é o lugar sagrado onde se produz a expressão da sua identidade religiosa e o culto sagrado. Para os turistas, seja ele religioso ou não, este espaço pode ser representado pelo local da última etapa de sua viagem. Os autores concluem que:

Para los peregrinos, las prácticas religiosas forman parte importante de todo el camino y sobre todo en la meta final - el santuario. Las oraciones y rituales son elementos imprescindibles de la peregrinación, mediante los cuales los creyentes ejercen la penitencia y la meditación. La percepción de la práctica religiosa por parte de los turistas comporta un carácter profano, y se entiende más bien como la oportunidad de nuevas experiencias, adquisición de conocimientos, incluso a veces se ve como divertimiento, pasatiempo o pura curiosidad. (SERRALLONGA; HAKOBYAN, 2011, p. 65).

Tanto a peregrinação quanto o turismo podem ser entendidos como fenômenos e estruturas de significados, que apontam para as distintas possibilidades de se vivenciar estas práticas religiosas. 


\section{Análise de Resultados}

Com base na revisão bibliográfica realizada, bem como a construção do estado da arte sobre o tema pesquisado, tem-se como produto um modelo teórico de análise que propõe a sistematização teórica entre as definições de 'peregrino' e 'turista religioso'. Procurou-se confrontar as diferentes definições para estes conceitos de acordo com a visão de diversos autores da área do turismo e de outros campos de estudo, além da visão da Igreja Católica acerca destas duas figuras.

O modelo teórico de análise proposto a seguir foi elaborado com base na pesquisa e análise artigos, dissertações e livros, nas línguas portuguesa, inglesa e espanhola. Dentre os trabalhos, destacam-se como os principais pesquisadores e autores da área do turismo religioso: Aragão e Macedo, Christoffoli, Carneiro, Dias, Cordeiro, Oliveira, Ribeiro, Sanchis, Seccal, Silveira, Steil e Vilas Boas.

Faz-se necessário saber que a sistematização é um conceito que vem sendo utilizado para designar uma forma metodológica de elaboração do conhecimento. Assim, sistematização é mais do que organização de dados, é um conjunto de práticas e conceitos que propiciam a reflexão e a reelaboração do pensamento, a partir do conhecimento da realidade. Entendendo então a sistematização como sendo uma interpretação crítica de diversos elementos, que a partir do ordenamento destes, gera um novo conhecimento, dando-se coerência a todos os elementos envolvidos.

Para a realização da sistematização teórica do tema estudado, foi construído um modelo teórico de análise contendo variáveis pertinentes para a delimitação das características e do perfil do peregrino e do turista religioso. Estas variáveis foram ponderadas e embasadas nos trabalhos acadêmicos pesquisados, sendo elas: motivação religiosa, prática de rituais Sagrados, função do deslocamento, sociabilidade, uso de infraestrutura turística, consumo de bens e serviços, prática do lazer e duração da viagem.

O modelo teórico de análise proposto representa um instrumento facilitador para diferenciar o peregrino do turista religioso. Na primeira coluna encontram-se as variáveis que delimitam e distinguem um ou outro personagem estudado. É interessante observar que cada variável assume uma característica diferente para o peregrino ou para o turista religioso. Na coluna do meio encontram-se as características pertinentes ao turista religioso, e na terceira coluna os atributos que dizem respeito ao peregrino. As expressões utilizadas na construção do modelo 
teórico de análise, como: moderado, demasiado, maior grau, menor grau, etc., foram assim escolhidas por melhor se encaixarem com a delimitação de cada variável proposta. Além disso, estas expressões buscam demonstrar a tendência que cada variável assume diante de cada ator, seja pra indicar uma tendência para mais ou para menos.

O modelo teórico de análise pode funcionar de duas maneiras. A primeira, mais abrangente, onde o indivíduo (pesquisador, acadêmico, leigo, profissional do turismo, etc.) pode olhar para o modelo de um modo mais generalizado e encontrar atributos e características gerais, seja do peregrino ou do turista religioso. Apenas pelo fato de observar essas características este indivíduo poderá diferenciar esses dois personagens, podendo aplicar estes atributos gerais para definir e identificar um peregrino ou turista religioso.

A segunda forma que o modelo pode ser utilizado é mais específica, onde um indivíduo (pesquisador, acadêmico, leigo, profissional do turismo, etc.) pode analisar de modo particular o deslocamento motivado pelo sagrado realizado por determinada pessoa, e ao considerar a motivação, características e atividades desempenhadas por este durante o seu deslocamento, de acordo com as variáveis propostas pelo modelo. Após analisada cada variável o indivíduo poderá avaliar se esta pessoa apresenta um perfil de peregrino ou turista religioso, contando se esta pessoa mostra mais características de um ou de outro.

A seguir apresenta-se o modelo teórico de análise que sistematiza a relação entre turista religioso e peregrino e em seguida será destrinchada e explicada cada variável presente no modelo.

Tabela 1: Modelo teórico de análise

\begin{tabular}{l|l|l}
\hline Variáveis & Turista Religioso & Peregrino \\
\hline Motivação Religiosa & Menor grau & Maior grau \\
\hline Prática de Rituais Sagrados & Moderado & Demasiado \\
\hline Função do Deslocamento & Meio & Fim \\
\hline Sociabilidade & Sim & Não \\
\hline Uso de Infraestrutura Turística & Demasiado & Moderado \\
\hline Consumo de Bens e Serviços & Demasiado & Moderado \\
\hline Prática do Lazer & Demasiado & Moderado \\
\hline Duração do Deslocamento & Curta & Longa \\
\hline
\end{tabular}

Fonte: O autor, (2015).

\section{A. Motivação religiosa}

Em relação à primeira variável alguns autores defendem que analisar a motivação é um dos elementos distintivos mais importantes na hora de identificar um peregrino ou turista religioso. 
Sendo assim, entende-se que o peregrino apresenta um maior grau de motivação religiosa. Para ele o sagrado representa o total da motivação do seu deslocamento.

Já o turista religioso também possui motivação religiosa, porém, em menor grau. Para este a religião e o sagrado representam apenas uma parte da motivação da sua viagem. Seu deslocamento geralmente está associado a outras motivações como, por exemplo, a prática do lazer, o consumo de bens e serviços, a socialização e troca de experiências, aquisição de novos conhecimentos, etc.

\section{B. Prática de rituais sagrados}

É possível observar nos peregrinos sinais e um semblante que expressa fé e entrega espiritual maior que no turista religioso. Os peregrinos vinculam a sua viagem ritos religiosos como: penitência, pagamento de promessas, orações, sacrifícios, etc. Outra questão pertinente à linguagem apresentada frequentemente pelos peregrinos é ideia de que para que a sua viagem valha a pena é preciso que ela esteja envolta de sofrimento e sacrifícios. Enquanto os turistas religiosos costumam realizar uma viagem com mais conforto e comodidade.

Observa-se que o turista religioso também apresenta a prática de rituais e atividades sagradas, porém, estas são realizadas de maneira moderada em comparação as praticadas pelo peregrino. Segundo Vilas Boas (2012, p. 40) as atitudes de fé do turista religioso surgem entrelaçadas com a "contemplação da natureza, da cultura, a deleite pela beleza do local, o enriquecimento do conhecimento e, até mesmo, a oportunidade de repouso". Entende-se então que enquanto o peregrino é movido pela procura da satisfação e conforto espiritual, buscando aumentar a sua religiosidade e obtenção de bênçãos, o turista além de participar, descomprometidamente nas atividades religiosas, acrescenta outras atividades a sua viagem.

\section{Função do deslocamento}

Observa-se que para o peregrino o deslocamento representa um fim, porque ele é movido pelo desejo de se aproximar espiritualmente do sagrado e de se relacionar com ele através do ato do seu deslocamento, do seu trajeto percorrido. Trata-se, neste caso, da figura do peregrino que pratica a sua viagem geralmente a pé, sozinho ou com um pequeno grupo de pessoas, e que utiliza poucos ou nenhum equipamento de infraestrutura turística. $\mathrm{O}$ peregrino realiza-se por estar no caminho e caminhando em direção ao sagrado.

Para o turista religioso, o deslocamento representa um meio para atingir o seu objetivo final, chegar a determinado destino e desempenhar determinadas atividades, ele utiliza a viagem 
como pretexto para experimentar outras realidades. O turista religioso realiza-se não no caminho ou no caminhar, mas sim em encerrar a sua viagem e chegar ao destino desejado.

D. Sociabilidade

É possível observar de forma geral que a viagem para o turista religioso assume um espaço para a socialização com outras comunidades e culturas, onde o contato com o outro é parte importante da experiência do deslocamento. Já o peregrino, assume geralmente uma postura de individualismo e austeridade, onde o mais importante para este é o deslocamento solitário ou em pequeno grupo, predominando a procura pelo sagrado.

Os turistas religiosos encontram no divertimento proporcionado pelas suas viagens, geralmente realizadas sob a forma de caravanas, grandes grupos e com ampla participação comunitária, momentos de descanso, de ruptura com o cotidiano, favorável ao contato familiar e social.

Nesse sentido, alguns estudos apontam as peregrinações associadas à ideia de um caminho percorrido baseado na dualidade: a busca do 'outro' (físico e/ou espiritual) e a procura de si mesmo. Configurando-se como uma jornada apontada para uma busca mística e para si mesmo, a procura de uma transformação interior vivenciada através do seu deslocamento.

E. Uso de infraestrutura turística

É evidente que estes dois personagens necessitam e utilizam a infraestrutura turística para a realização de suas viagens e deslocamentos, seja a infraestrutura turística básica em termos de transportes, alimentação, serviços urbanos, ou a infraestrutura turística específica abrangendo hospedagem, lazer, entretenimento, etc.

Porém, o que diferencia estes dois personagens é a atitude que estes assumem diante do uso da infraestrutura turística. Observa-se que para o turista religioso a infraestrutura é parte fundamental e indispensável para a realização de sua viagem, visto que este geralmente procura comodidade e conforto em seus deslocamentos.

Já o peregrino também se utiliza da infraestrutura turística, porém esta não é indispensável para ele. Como visto anteriormente, o peregrino geralmente realiza seus deslocamentos pautados na austeridade, onde o sofrimento, a falta de comodidade e o mínimo de conforto são elementos fundamentais para que a experiência valha a pena e seja recompensadora.

F. Consumo de bens e serviços 
De antemão, é possível afirmar que existe a presença do consumo na viagem com fins religiosos, que podem ser comuns tanto ao turista religioso quanto ao peregrino, o diferencial entre eles está na atitude que cada um assume diante o consumo.

Observa-se que o turista religioso apresenta um consumo demasiado de bens e serviços. Percebe-se que este consumo além de ser maior em quantidade, em número de bens e serviços, é também mais elevado no que diz respeito ao valor gasto. $\mathrm{O}$ turista religioso além dos gastos com necessidades básicas como hospedagem e alimentação, gasta também com lazer e entretenimento, bem como com souvenirs, artigos religiosos, e em muitos casos com produtos e bens variados, que vão desde vestuário até artigos para casa.

Em contrapartida, uma marca característica do peregrino é a sua moderação no que diz respeito ao consumo de bens e serviços. Pode-se observar um consumo considerados mais básicos como, por exemplo, alimentação, transporte e hospedagem, porém o peregrino assume uma atitude mais moderada no que diz respeito ao consumo de produtos e artigos considerados por estes como sendo supérfluos e dispensáveis.

\section{G. Prática do lazer}

Observa-se que para o turista religioso a viagem ganha ares de celebração e festa, onde este não desfruta apenas de experiências espirituais, mas também de um acontecimento social. $\mathrm{O}$ turismo religioso é visto como uma oportunidade de unir o lazer com a religião. E em muitos casos o caráter do lazer e divertimento acaba por se igualar, ou até muitas vezes se sobrepor ao caráter religioso.

Abumanssur (2003, p. 6) acredita que "o peregrino é movido pela busca da satisfação e conforto espiritual, $[. .$.$] enquanto o turista busca o bem estar, muitas vezes a preguiça, a satisfação através$ do lazer". Observa-se então que apesar de em alguns casos o peregrino utilizar o seu tempo para o descanso ou a prática de atividades de lazer, estes elementos não estão sempre presentes em suas viagens nem são o caráter motivador primordial em seus deslocamentos.

\section{H. Duração do deslocamento}

Santos (2006, p. 280) aponta esta variável como sendo um “critério acessório" para diferenciar o turista religioso que "tendencialmente demoram menos tempo no lugar sagrado de destino", do peregrino que normalmente desprende mais tempo para realizar as suas viagens. Santos (2006, p. 280) completa ainda dizendo que "o tempo religioso está também influenciado pelo calendário religioso" e por isso, tanto as viagens turísticas quanto as peregrinações são empreendidas de acordo com grandes eventos de natureza religiosa. Em resumo, pode-se dizer 
que devido a sua maior entrega e busca pelo sagrado o peregrino consequentemente também dedica um tempo maior a realização de suas viagens. Já o turista religioso em uma viagem de curta duração consegue atingir seus objetivos e necessidades.

\section{Considerações Finais}

Diante do exposto observou-se que os termos referentes a turista religioso e peregrino são empregados por muitos autores como sendo sinônimos, em outros casos como sendo conceitos distintos. Em alguns trabalhos, observou-se que os autores apresentam ambiguidades e imprecisões epistemológicas quanto ao uso de categorias temáticas ligadas ao turismo religioso. Desse modo, a falta de conhecimento sobre o assunto, seja por parte dos pesquisadores seja por parte de leigos, impedem o pleno desenvolvimento e planejamento do turismo religioso e o bom acordo e interação entre as partes que atuam neste segmento.

É possível dizer que o paradigma que norteia a peregrinação e o turismo religioso pode ser analisado segundo dois pontos de vista. Primeiro o da religião, que analisa o peso do caráter religioso e sagrado para estes dois personagens, e segundo, o das ciências sociais que analisam outras questões que motivam estas viagens como, por exemplo, o lazer, o desfrute e a utilização dos equipamentos turísticos.

Entende-se que os deslocamentos religiosos configuram-se como fenômenos que em um sentido tradicional poderiam ser denominadas de peregrinações, mas que no contexto atual da sociedade moderna, se constitui em um espaço atrativo por assumir também um aspecto turístico e de lazer. Neste sentido ao invés de entender o universo do turismo como exterior ao universo da peregrinação ou achar que, por serem universos distintos, o turismo poderia introduzir elementos alheios e deturpar um sentido "original" de peregrinação, é mais proveitoso compreender o diálogo e as possíveis tensões entre estes dois campos, como o surgimento de uma expressão moderna de "peregrinação" chamada de turismo religioso.

Pode-se afirmar, através de uma analogia, que o turismo religioso e a peregrinação são como dois caminhos paralelos, que apresentam características e valores distintos, mas que estão bastante próximos. O viajante motivado pelas questões religiosas tem o poder de transitar e alternar entre estes dois caminhos muito facilmente, sem mesmo perceber que está mudando de caminho. Com isso, procura-se afirmar que o peregrino e turista religioso apresentam comportamentos e características muito parecidas em uma primeira observação, porém, através 
de uma análise mais aprofundada e com um olhar mais crítico é possível apontar as sutis diferenças que distinguem o peregrino do turista religioso.

Destaca-se a importância do papel do turismólogo na hora de sistematizar, planejar e refletir em nível teórico e prático, as questões ligadas ao turismo religioso, ou demais segmentos em que este seja chamado a atuar. Lembrando sempre de estar atento às questões culturais, sociais, e toda a simbologia e valores envoltos a religião.

Entende-se que o campo dos deslocamentos motivados pela religião é bastante complexo e apenas uma definição ou delimitação do ato de deslocamento e daquele que pratica (o viajante) não seria suficiente para sanar e satisfazer as necessidades existentes. Porém é possível afirmar que existem elementos comuns ao turismo ou peregrinação, visto que todo deslocamento religioso implica numa tríplice estrutura. Sendo um indivíduo que transita por uma rota; um destino (meta), escolhido por sua relação com o sagrado; e, uma motivação para encontrar-se com a realidade mística e sagrada.

Através da construção do modelo teórico de análise contendo a sistematização teórica acerca da diferença entre peregrino e turista religioso, foi possível constatar que por meio da análise mais profunda de variáveis e características que dizem respeito a estes dois atores pode-se chegar a uma definição mais adequada para aquele que pratica o deslocamento motivado pela religião.

Acredita-se que a peregrinação pode ser um dos elementos presentes dentro do turismo religioso ou existir por si só. Sendo o principal elemento distintivo entre estes, a motivação religiosa destas personagens, entendendo que cada uma delas tem o seu campo de ação, nível de entrega ao sagrado e um grau diferente de imersão em suas experiências.

Este trabalho pretende ser um passo de uma caminhada de reflexão e estudos ainda incipientes acerca do fenômeno crescente do turismo religioso e das peregrinações, mais precisamente da figura do turista religioso e peregrino. Diante da crescente mobilidade de pessoas, e a busca constante por algo novo, o turismo religioso configura-se como elemento provedor de caminhos, encontros, e aproximação entre os indivíduos e entre estes e o Sagrado. O turismo religioso podese tornar uma importante plataforma geradora de fraternidade, igualdade e paz entre povos distintos, a estrutura onde turistas e peregrinos encontram diferentes caminhos ao Sagrado. 


\section{Referências}

ABREU, Tereza N. M. de; CORIOLANO, Luzia N. M. T. Os centros de romaria do Ceará e o turismo religioso. In: CORIOLANO, Luzia N. M. T. (Org.). O turismo de inclusão e o desenvolvimento local. Fortaleza: FUNECE, 2003. p. 78-95.

ABUMANSSUR, Edin Sued. Religião e turismo. Notas sobre as deambulações religiosas. In: ABUMANSSUR, Edin Sued (Org.). Turismo religioso. Ensaios antropológicos sobre religião e turismo. Campinas: Papirus, 2003.

ANDRADE, José V. de. Turismo fundamentos e dimensões. São Paulo: Ática, 2000.

ARAGÃO, Ivan; MACEDO, Janete. São Cristóvão e Divina Pastora: Lócus do turismo religioso em Sergipe - Brasil. Penedo, v. 1, n. 1, p. 34-46, 2011.

BENI, Mário Carlos. Análise estrutural do turismo. 3. ed. São Paulo: SENAC, 2000.

BRASIL. Ministério do Turismo. Turismo religioso continua em alta no Brasil. Disponível em: <http://www.turismo.gov.br/turismo/noticias/todas_noticias/20150112_2.html>. Acesso em: 20 abr. 2015.

BRASIL. Turismo cultural: orientações básicas. Ministério do Turismo, Secretaria Nacional de Políticas de Turismo, Departamento de Estruturação, Articulação e Ordenamento Turístico, Coordenação Geral de Segmentação. Brasília, 2. ed., 2008.

CARNEIRO, Sandra Maria Corrêa de Sá. Novas peregrinações brasileiras e suas interfaces com o turismo. Porto Alegre, v. 6, n. 6, p. 71-100, 2004.

CHRISTOFFOLI, Angelo; PEREIRA, Raquel; SILVA, Yolanda. O Lazer no Turismo Religioso: uma análise dos discursos no Turismo. Espanha, v. 10, n. 5, p. 595-603, 2012.

COLLI, Eduardo. Universo Olímpico: Uma Enciclopédia das Olimpíadas. São Paulo: Codex, 2004.

COSTA, D. C.; ROCHA, T. V. C.; BELCHIOR, M.H.C. da. Impactos dos eventos religiosos sobre a cadeia produtiva do turismo: Um estudo de caso aplicável à Jornada Mundial da Juventude Rio 2013. In: $26^{\circ}$ Congresso Brasileiro de Empresas e Profissionais de Eventos, 2014, São Paulo. Anais do $26^{\circ}$ Congresso Brasileiro de Empresas e Profissionais de Eventos, 2014.

DEMO, Pedro. Metodologia do conhecimento científico. São Paulo: Atlas, 2000.

DIAS, R. O turismo religioso como segmento do mercado turístico. In: DIAS, R. SILVEIRA, E. J. S. da (Orgs.). Turismo Religioso: Ensaios e reflexões. Campinas: Alínea, 2003, p. 7-37.

DIAS, R.; SILVEIRA, E. J. S. da. Turismo Religioso: Ensaios e reflexões. Campinas: Alínea, 2003.

G1. Turismo religioso estimula economia de mais de 300 cidades do país. Disponível em: < http://g1.globo.com/economia-e-negocios/noticia/2010/09/turismo-religioso-estimula-economia-demais-de-300-cidades-do-pais.html>. Acesso em: 25 abr. 2015, 10:23.

GIL, Antonio Carlos. Como elaborar projetos de pesquisa. 4. ed. São Paulo: Atlas, 2008.

GUERRA, Luciano. O turismo religioso no mundo de amanhã. Lisboa: instituto de novas profissões. Lisboa: Gabinete de Estudos Turísticos, 1989.

IBGE (2010). Censo 2010: número de católicos cai e aumenta o de evangélicos, espíritas e sem religião. Disponível em: <http://saladeimprensa.ibge.gov.br/noticias?view=noticia\&id $=1 \&$ busca=1\&idnoticia=2170>. Acesso em: 22 abr. 2015 .

MICHAELIS: Dicionário escolar língua portuguesa. 2. ed. São Paulo: Editora Melhoramentos, 2008. $951 \mathrm{p}$.

NADAIS, Catarina Duarte Fontana. O turismo e os territórios da espiritualidade: Os caminhos de Santiago em Portugal. Dissertação de Mestrado, Faculdade de Letras da Universidade de Coimbra, Programa de Pós-Graduação em Lazer, Património e Desenvolvimento, Coimbra: 2010. Disponível em: 
<https://estudogeral.sib.uc.pt/bitstream/10316/15370/1/Disserta\%C3\%A7\%C3\%A3o\%20mestrado_Ca tarina\%20Nadais.pdf >. Acesso em: 03 jun. 2015.

OLIVEIRA, Christian Dennys Monteiro de. Turismo Religioso. São Paulo: Aleph, 2004.

PORTAL BRASIL. Cidades-polo do turismo religioso no Brasil vão receber investimentos. Disponível em: <http://www.brasil.gov.br/turismo/2013/09/cidades-polo-do-turismo-religioso-no-brasil-vaoreceber-investimentos>. Acesso em: 25 abr. 2015.

RIBEIRO, Cristiane Menezes. Turismo Religioso: fé, consumo e mercado. E-Revista Facitec, Distrito Federal, v. 5, n. 1, ago. 2010.

RIBEIRO, Heloisa. Andar com fé e o sentido do chegar. Rio de Janeiro: Caderno Virtual de Turismo, v.3, n.1, p 1-7, 2003.

SANTOS, Glauber Eduardo de Oliveira. Importância das Peregrinações para o Turismo Mundial. São Paulo: Turismo em Análise, nov. 2000, p. 38-44.

SANTOS, Maria da Graça Lopes da Silva Mouga Poças. Espiritualidade, Turismo e Território, Estudo Geográfico de Fátima. Lisboa: Principia, 2006.

SERRALLONGA, Silvia; HAKOBYAN, Karine. Turismo religioso y espacios sagrados: una propuesta para los santuarios de catalunya. Penedo: Revista Iberoamericana de Turismo, v. 1, n. 1, p. 63-82, 2011.

SILVA, Edna Lúcia da; MENEZES, Estera Muszkat. Metodologia da pesquisa e elaboração de dissertação. Florianópolis: UFSC, 2005. 138 p.

SILVEIRA, Emerson J. Sena da. Turismo religioso, mercado e pós-modernidade. In: DIAS R. e SILVEIRA E. J. S. da (Orgs.). Turismo religioso: ensaios e reflexões. Campinas: Alínea, 2003, p. 39-90.

SILVEIRA, Emerson J. Sena da. Turismo Religioso no Brasil: uma perspectiva local e global. São Paulo, v. 18, n. 1, p. 33-51, maio 2007.

SILVEIRA, Emerson J. Sena da. Turismo religioso popular? Entre a ambiguidade conceitual e as oportunidades de mercado. Espanha: Revista de Antropologia Experimental, n. 4, 2004.

STEIL, Carlos Alberto. Peregrinação e turismo: o natal em gramado e canela. Anais XXII Reunião Anual da ANPOCS. Caxambú: 1998. Disponível em: <http://www.clacso.edu.ar/ libros/anpocs/steil.rtf>. Acesso em: 27 mai. 2015.

STEIL, Carlos Alberto. Romeiros e turistas no santuário de Bom Jesus da Lapa. Porto Alegre: Horizontes Antropológicos, v. 9, n. 20, p. 249-261, out. 2003.

VILAS BOAS, Nuno Fernando de Sá. A Pastoral do Turismo: Da peregrinação ao santuário. Braga: 2012.

\section{Recebido em: 28/03/2016 (1 ${ }^{\text {a }}$ versão)}

Aprovado: 27/07/2016 